\title{
Design of a Dairy Cooling Thermal Storage supported with Secondary Refrigeration Cooling Unit
}

\author{
Ali Alahmer ${ }^{1 *}$, Sameh Alsaqoor ${ }^{1}$ \\ ${ }^{I}$ Department of Mechanical Engineering/Tafila Technical University, Tafila, Jordan
}

\begin{abstract}
This manuscript presents the comparison of using the cold water and brine as a storage source of refrigeration for milk cooing process based on the accumulator volume and power consumed at variable of cooling load. Also presents the effective of using cold storage in term of accumulator to reduce the refrigeration capacity and energy saving.This manuscript begins with a derivation of mathematical model represents of cooling system followed with a computer program to integrate and simulate the appropriate equations to evaluate accumulator volume and power required for water and brine system. The results showed that the accumulator volume using cold water was $58 \mathrm{~m}^{3}$ and $59.21 \mathrm{~m}^{3}$ for cold brine at the same conditions with $206 \mathrm{~kW}$ of maximumcooling load, peak duration of 3.5 hours, water temperature difference $2^{\circ} \mathrm{C}$, and operating period of refrigerating unit up to 17 hours a day. Also, it was found the power required to operate the compressor of water system around $45 \%$ less than the power needed to operate the compressor of cold brine system.
\end{abstract}

Keywords: accumulator, cooling load, milk, peak duration, thermal storage.

\section{Introduction}

Milk is important sources of protein and calcium which helps us in building muscles. Dairy is one of the five groups in the official food guide pyramid. Dairy includes milk and milk products like yogurt and cheese. A $225 \mathrm{ml}$ of milk provides a big percentage of your recommended daily allowance of vitamins and minerals as shown in table 1 . The cows can be produced high amount of milk and it could be milked many times a day. The average cow produces 90 glasses of milk a day. To make 9 gallons of milk a day, a cow must drink 18 gallons of fresh and clean water ( 2 gallons of water for every gallon of milk), and the cow needs 500 gallons of blood to pass through it udder to make one gallon of milk [1].

Milk leaves the cow at $101 \square \mathrm{F}(38 \square \mathrm{C}$ ) and is promptly cooled and store at $40 \square \mathrm{F}(4 \square \mathrm{C}$ ) so that there mechanisms (cooling unit) should be used to achieve the temperature requested quickly to avoid milk wasted.To avoid the good environment for bacteria lives, the milk directly should be cooled after cow milking. The capacity of refrigeration must be sufficient to cool 50 percent of its total volume of milkreceived from 38 to10 $\square \mathrm{C}$ during the first hour, and from 10 to $4.4 \square \mathrm{C}$ during the second hour. After that milk is usually delivered to a dairy plant in an insulated stainless steel tank on a truck to make pasteurization operation [2].

From above facts, the milk should have the suitable and accurate treatment to keep it useful, healthy and suitable to consume. In our manuscriptwe designed an accumulator or thermal storage device to store the thermal energy at lean load and use it at the peak load during cooling the milk. We begin, in section two, with a discussion of thermal storage. The description of refrigeration milk plant was displayed in section three. In section four, we present our research methodology in form of mathematical model and computer simulation. Section five presents the results and the discussion; while section six summarizes the study findings through the conclusion.

Table 1: Some recommended daily allowance vitamins and minerals that milk provides.

\begin{tabular}{c|c} 
Mineral Materials & Percentage \\
\hline Protein & $17 \%$ \\
Calcium & $29 \%$ \\
Phosphorus & $23 \%$ \\
Riboflavin & $23 \%$ \\
Vitamin d & $25 \%$ \\
Vitamin b-12 & $15 \%$
\end{tabular}

\section{Thermal Storage}

Thermal storage can be used for applications which the peak load's confined to limited number of hours in a day and the load for a few other working or operating hours is much less. In the balance time of 24 hours, there is no load whatsoever. Typical examples are process applications such as milk processing. In milk processing, the requirements of refrigeration is limited generally from six to eight hours a day, and there is no load during the balance period of 24 hours [3].Design a refrigeration unit at the conditions of maximum cooling 
load of milk (peak load) means that there will be need to large compressor, accordingly more power required for operating. To meet the peak load limited to a few hours, the accumulator or thermal storage should be used to make the refrigeration plant work up to 17 hours a day. During the lean load periods and particularly in the zeroload hours; the refrigeration plant can be operated to generate thermal storage in the form of cold water or cold brine. This system reduces the size of the compressor. As a result the power requirement of compressor is reduced [4-6].

To achieve the optimal refrigeration design plant, the volume of cold water/brine accumulator, the power consumed, and capacity of refrigeration unit must be considered.There are two ways to achieve either by experiments or by computer-based simulation. The computer simulation is preferable because it saves time and money.

\section{Refrigeration Milk Plant Description}

This section presents the main components of the refrigeration plants to supply milk using accumulator by water or brine. The refrigeration milk plant consists of the main parts, which are milk tank, three centrifugal pumps, milk filter, heat exchanger, milk regulator, accumulator, vapor compression cycle components (evaporator, expansion valve, condenser, and compressor) and finally cold milk tank. The description of the main components are presented in table 2.

The schematic diagram of refrigeration supply of milk plants based on automated or thermal storage using water or brine is shown in figure 1.The refrigeration cycle is set according to the following steps: (i) Warm water/brine leaves the heat exchanger after cooling the milk and enters the accumulator in warm chamber (I);(ii) The warm water/ brine pumped by pump (8) to the refrigeration unit which heat is transferred from the water to R-22 for water, and brine for ammonia in the evaporator; (iii) By this way, the chilled water/brine for cooling milk was obtained and enters into the accumulator chamber (II); (iv)in case no load, pump (6) will not be running so the water keep on cooling until the two chambers (I) and (II) of the accumulator be filled with the chilled water/brine which happened also by the water/brine flood from chamber (II) to chamber (I) through the upper gap;(v) In the case of peak or lean load pump (6) will be running but pump (8) runs when the stored energy is not enough to remove the load; (vi) By this way, the system will be ready to receive new load and achieve the purpose of the accumulator;(vii) when new load received the cooled water pumped by the centrifugal pump (6) to the heat exchanger (4) which heat is transferred from the milk to the cold water, then water will be return back to the accumulator chamber (I) and the cycle repeated.

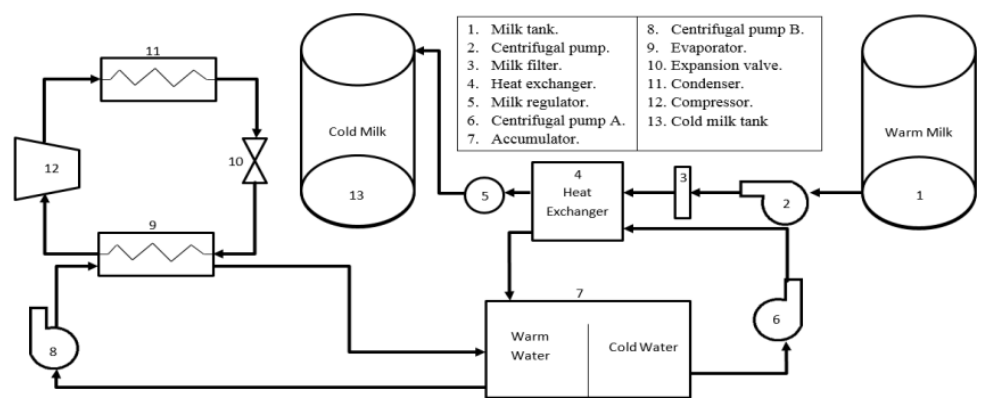

Fig.1 Schematic diagram of the diary refrigeration plant.

Table 2: List of main refrigeration plant components.

\begin{tabular}{|c|c|}
\hline Component (Location) & Description \\
\hline Heat Exchanger (4) & $\begin{array}{l}\text { - } \quad \text { Remove the heat from the warm milk to chilled water. } \\
\text { - } \quad \text { Shell and tube type, cross flow, milk in tube and water/brine in shell } \\
\text { - } \quad \text { It made of stainless steel } 316 .\end{array}$ \\
\hline Centrifugal Pump (6) & $\begin{array}{l}\text { - Circulate the water/brine from cold chamber to the warm chamber throw the heat cool. } \\
\text { - it made of cast steel and it design at the max load }\end{array}$ \\
\hline Accumulator (7) & $\begin{array}{l}\text { - } \quad \text { Divided into two equal chambers: warm water (I) and cold water (II). } \\
\text { - } \\
\text { - } \\
\text { The accumulator isolated from all sides. } \\
\text { - The purpose of the accumulator is to save energy consumption by accumulate amount of } \\
\text { - } \quad \text { Accumulator leads to use smaller compressor for the refrigeration unit. }\end{array}$ \\
\hline Centrifugal Pump (8) & $\begin{array}{l}\text { - Circulate the water /brine from warm chamber to cold chamber throws the refrigerator. } \\
\text { - It made of cast steel, and it designat the lean load. }\end{array}$ \\
\hline Tubing & $\begin{array}{l}\text { - Most tubing used in refrigeration systems are made of copper. However, aluminum, steel, } \\
\text { stainless steel, and plastic tubing are being used also. } \\
\text { - }\end{array}$ \\
\hline Refrigeration Unit (9-12) & $\begin{array}{l}\text { - Vapor compression refrigeration cycle, which involves four main components: a } \\
\text { compressor, a condenser, an expansion valve, and an evaporator. }\end{array}$ \\
\hline
\end{tabular}




\section{Calculation Method}

This part is aimed to determine the power consumed and the energy saving ratio for water/ brine cooling system. For this purpose a minimum volume of refrigeration accumulator required to meet the peak load and the capacity of refrigeration unit during the peak load periods must be calculated. Two assumptions were taken in our calculation: For the capacities, power, and volume calculations, all equipment's will be based on the max load; and (ii) all the components will be isolated. Now, consider a simplified schematic diagram of the plant as shown in figure 2 which accumulator consists of well-insulated two-side tank, warm and cold, the calculation method of water-storage system is expressed as follows:

The refrigeration capacity Qo $(\mathrm{kW})$ is defined as:

$\mathrm{Qo}=[(\mathrm{Gwcp} \cdot \tau \max +$ Gwca $\cdot \tau \min ) \mathrm{Cw} \Delta \mathrm{twc}] /(\tau \max +\tau \min )$

Where; $\tau$ maxis the duration of the longest peak period (hour), $\tau$ minis the duration of the shortest lean load (hour), Gwcpis the mass flow rate of water through milk cooler under peak load conditions (kg/sec), Gwca is the mass flow rate of water through milk cooler for average load of milk in 24 hours $(\mathrm{kg} / \mathrm{sec}), \mathrm{Cw}$ is the specific heat of water $(4.1868 \mathrm{~kJ} / \mathrm{kg}$. $\square \mathrm{C})$, and $\Delta \mathrm{twc}$ is the temperature difference of water at inlet and outlet of milk cooler (hour).

The mass flow rate of water through milk cooler under peak load condition Gwcp and for average load of milk in 24 hours Gwca is defined respectively as

Gwcp $=\mathrm{Qmm} /(\mathrm{Cw} \cdot \Delta \mathrm{twc})$

Gwca $=\mathrm{Qma} /(\mathrm{Cw} . \Delta \mathrm{twc})$

Where; Qmm is the maximum load of milk $(\mathrm{kW})$, Qmais the average load of milk in 24 hours $(\mathrm{kW})$.

To find the volume of accumulator, it is necessary to determine the mass flow rate of water through evaporatorGwc $(\mathrm{kW})$, which expressed as:

$\mathrm{Gwc}=\mathrm{Qo} /(\mathrm{Cw} . \Delta \mathrm{twe})$

Where; $\Delta$ tweis the temperature difference of water at inlet and outlet of evaporator $(\square \mathrm{C})$. Once Gwcis found then volume of accumulatorVac $\left(\mathrm{m}^{3}\right)$ is determined by the following equation:

$\operatorname{Vac}=(($ Gwcp. $\Delta \mathrm{twc}-$ Gwe. $\Delta$ twe $) \tau \max ) /(\rho w .(\operatorname{tmax}-\operatorname{tmin}))$

Where; $\rho$ wis the density of water $\left(1000 \mathrm{~kg} / \mathrm{m}^{3}\right)$, tmaxis the maximum temperature of water in accumulator ( $\square$ C), andtminis the minimum temperature of water in accumulator $(\square \mathrm{C})$.

As a result of peak load, the temperature of water in accumulator is increased (accumulatordischarge).

To determine the temperature of water at any given duration of peak load Tw1 ( $\square$ C), the following equation is used:

$\mathrm{Tw} 1=\operatorname{tmin}+[((\mathrm{Gwcp} . \Delta \mathrm{twc}-\mathrm{Gwe} . \Delta \mathrm{twe}) \tau 1) /(\rho \mathrm{w} . \mathrm{Vac})]$

Where; $\tau 1$ is the given duration of peak load $(\square \mathrm{C})$ restricted within the range of $(0 \leq \tau 1 \leq \tau$ max).

On the other hand, the temperature of water in accumulator is decreased (accumulatorcharge) during the lean period.In this case the following equation is used to find out the temperature of water during the charge period Tw2 $(\square \mathrm{C})$ :

$\mathrm{Tw} 2=\mathrm{tmax}+[(($ Gwca. $\Delta$ twc - Gwe.$\Delta \mathrm{twe}) \tau 2) /(\rho \mathrm{w}$. Vac $)]$

Where; $\tau 2$ is the given duration of lean load $(\square \mathrm{C})$ restricted within the range of: $(0 \leq \tau 2 \leq \tau \mathrm{min})$.

To findthe duration of operating period of refrigeratingunit $\tau$ wn (hour) is expressed by the following equation:

$\tau w n=($ Qma.24.60.60)/( Qo .60.60)

As well, the ratio of operating period a daybwm is determined as:

bwm $=\tau \mathrm{wm} / 24$

Taken into account that the refrigerant used to cool the water being circulated through coils in the evaporator is (R22), thus the refrigerating effect and work of compression per $(\mathrm{Kg})$ are determined at evaporator temperature of (268 k) which is recommend by [7], and condensing temperature of $303 \mathrm{~K}$ once refrigerating effect is determined, the mass flow rate of refrigerant $\mathrm{GR}\left(\mathrm{m}^{3}\right)$ is obtained as follows:

$\mathrm{GR}=\mathrm{Qo} / \mathrm{qo}$

Thus theoretical power NT $(\mathrm{kW})$ is calculated as:

$\mathrm{NT}=\mathrm{GR}$.W

Where; $\mathrm{W}$ is the compression work per $\mathrm{Kg}(\mathrm{kJ} / \mathrm{kg})$.

The energy conservation of water accumulation system is assessed by calculation the energy saving ratio ECE as follows:

$\mathrm{ECE}=(\mathrm{NTM}-\mathrm{NT}) / \mathrm{NTM}$

Where; NTM is the theoretical power at the conditions of maximum load (peakload) of milk (kW), which is determined as follows:

First, the mass flow rate of refrigerant GRM $(\mathrm{kg} / \mathrm{sec})$ is determined at the condition of $(\mathrm{Qmm})$ as:

GRM=Qmm / qo

Thus, 


\section{NTM=GRM.W}

To calculate the volume of accumulator, the refrigeration capacity, temperature of water in accumulator, theoretical power, and the energy saving ratio, comparison between water accumulation system and brine accumulation system a computer program is written.

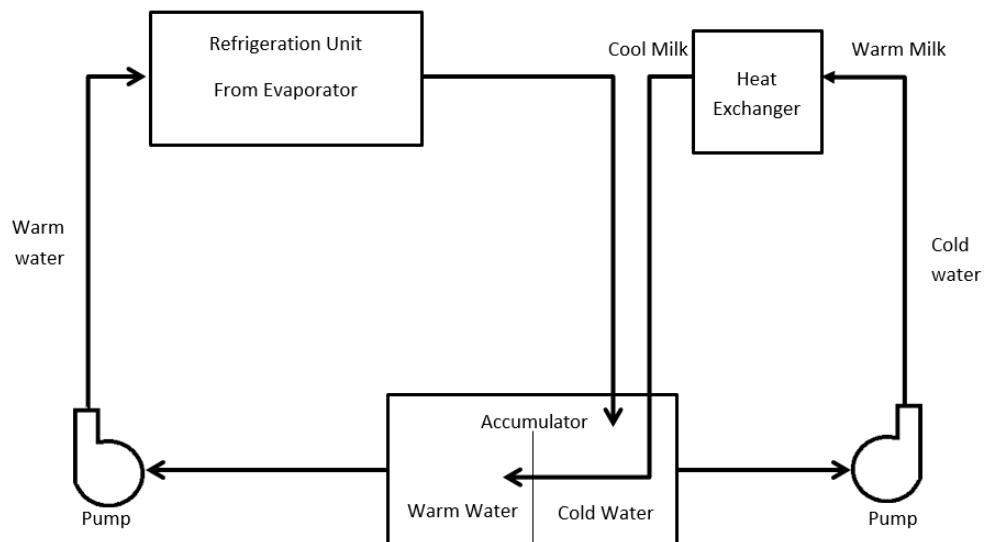

Fig.2: Simplify Schematic diagram of the main refrigeration components.

\section{Results and Discussion}

In order to improve the cold water/ brine accumulation system for milk plant, the mathematical model can be used to study the effect of varying some of the design parameters. The results outlined below are based on (206 kW) maximum cooling load of milk, $(2 \square$ C) storage source(water or brine) temperature difference between the inlet and outlet of milk cooler . As well $(2 \square \mathrm{C})$ temperature variation of storage source in accumulator, $(1 \square \mathrm{C})$ minimum temperature and $(3 \square \mathrm{C})$ maximum temperature of storage source in accumulator, $(2 \square$ C) storage source temperature difference between the inlet and outlet in evaporator, (R22) primary refrigerant for cold water accumulation system, and ammonia refrigerant for cold brine accumulation system.

After the using of the developed model based on the average cooling load of milk (100kW), the theoretical power required (NT) is calculated and illustrated with duration of peak load and cooling load ratio $(\mathrm{Qma} / \mathrm{Qmm})$ in figure 3 and 4 respectively. The energy saving ratio $\mathrm{E}_{\mathrm{CE}}$ is calculated and shown with duration of peak load and duration of lean load in figure 5 and 6 respectively. As well the energy saving ratio is depicted with cooling load ratio (Qma / Qmm) in figure 7. In addition to that, the effect of peakload duration on the accumulator volume is displayed in figure 8. Finally the effect of cooling load ratio (Qma / Qmm) on the coefficient of performance is presented in figure 9 .

The results of this study demonstrates that using the cold water as a storage source in milk plant requires less power than brine. The theoretical power is reduced around $45 \%$ as shown in figure 3 and 4 . The duration of peak load seems to have some influence on the power requirements and energy saving ratio, figures 3 and 5. So theincreasing of peak load duration leads to an increasing in the power requirements and a drop in the energy saving efficiency. In addition to that a long duration of peak load calls for very large chilled storage source accumulators is illustrated in figure 8. The reduction of the average cooling load of milk (Qma) according to the maximum load $(\mathrm{Qmm})$ is reflected to achieve the less theoretical power of compressors and the higher energy saving percentage as demonstrated in figures 4 and 5. Figure 6 indicates that the longer lean load period the greater energy saving percentage. This will be lead to use aless capacity of refrigeration unit to generate the accumulator during the lean load period. Figure 7 shows the volume of accumulator in case of water as secondary refrigerating refrigerant is closely to the brine accumulator at any conditions of milk cooling load. Finally as the cooling load ratio increases (Qma / Qmm) the coefficient of performance decreases as shown in figure 9. 


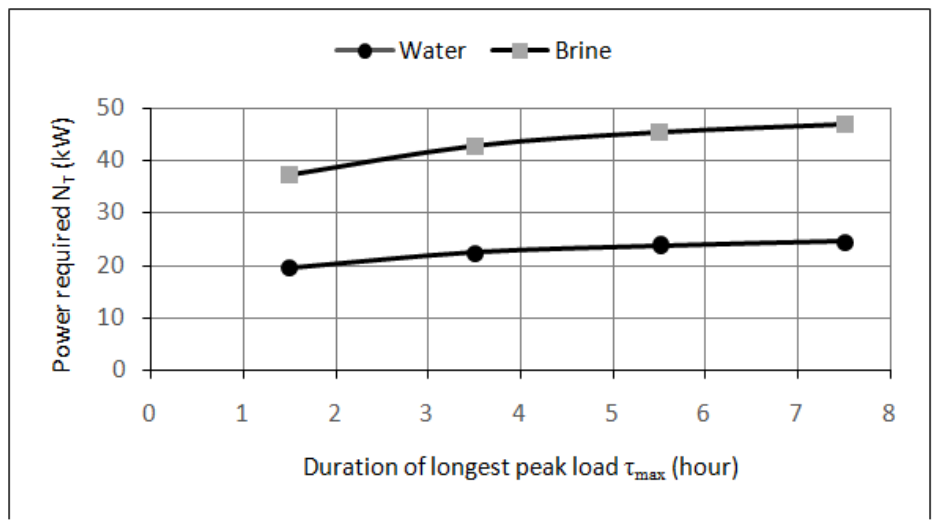

Fig.3: Effect of the peak load duration on the power required for water and brine system.

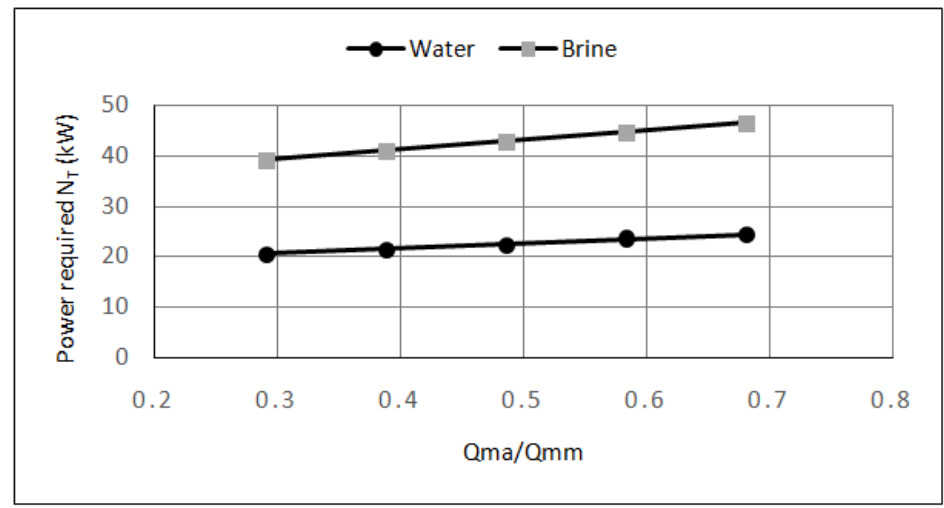

Fig.4: Effect the cooling load ratio on the power required for water and brine system.

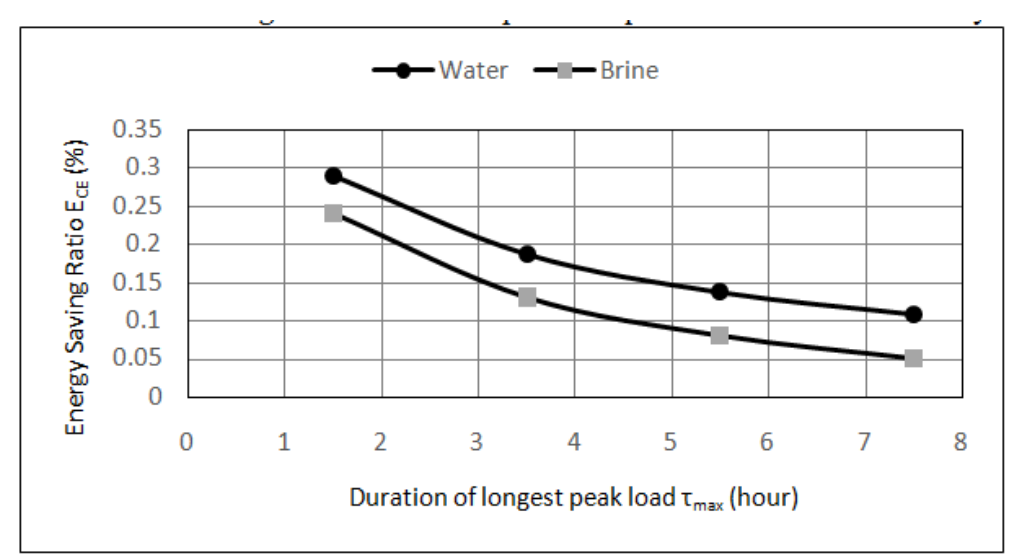

Fig.5: Effect of the peak load duration on the energy saving ratio for water and brine system.

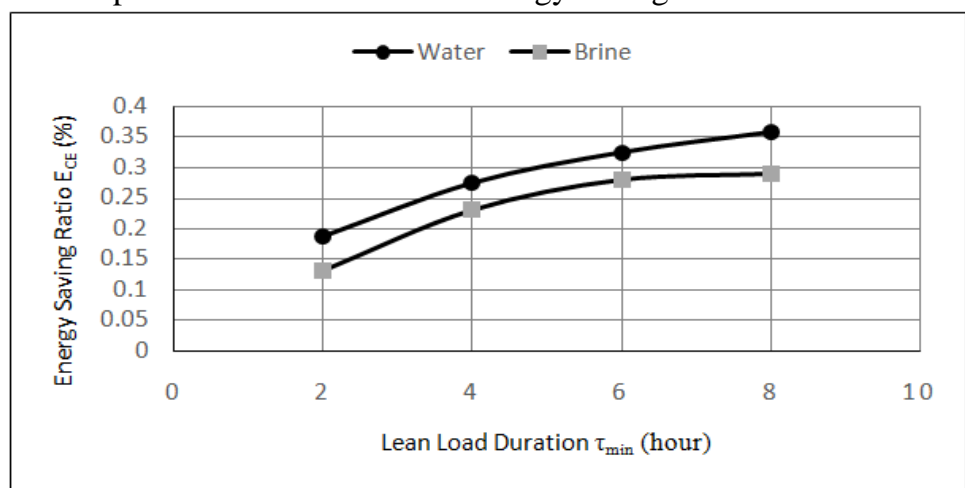

Fig.6: Effect of the lean load duration on the energy saving ratio for water and brine system. 


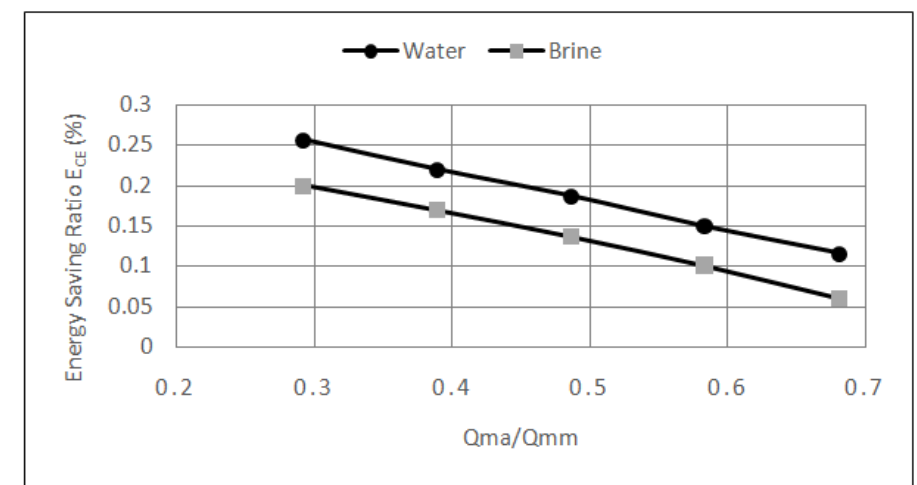

Fig.7: Effect of the cooling load ratio on the energy saving ratio for water and brine system.

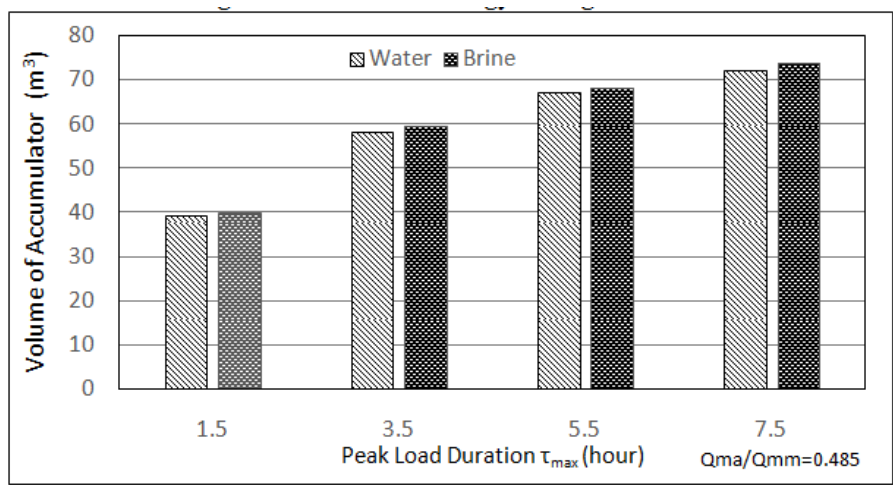

Fig.8: Effect of the peak load duration on the volume of accumulator for water and brine system.

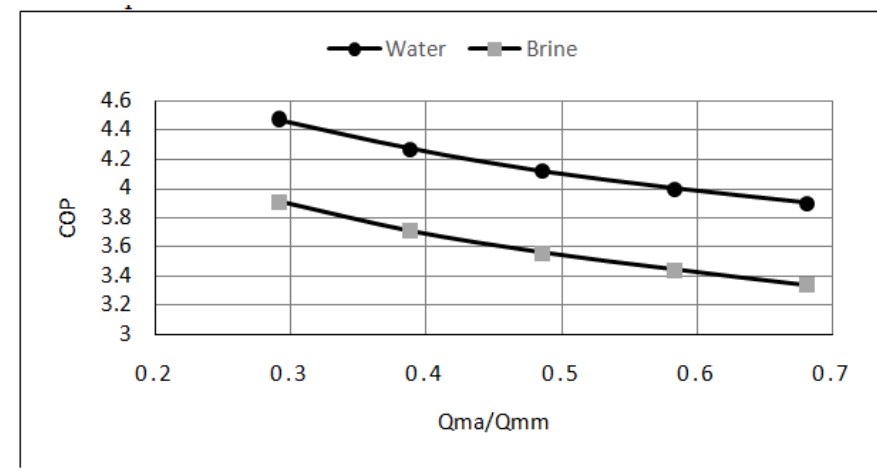

Fig.9: Effect of the cooling load ratio on the coefficient of performance for water and brine system.

\section{Conclusion}

We elucidated in great detail our optimal design strategy using of cold water and brine as a storage source of refrigeration for milk cooing process based on the accumulator volume and power consumed at variable of cooling load. This study results can be usefully summarized into following points;

- The water accumulation system should be used instead of brine accumulation system.

- The power required for cold-water accumulation system is substantially lower than that for the cold-brine accumulation system. Such that a $45 \%$ decrease in power required for operating the compressors at any conditions of peak and lean load of milk. It can be attributed to high large density and viscosity of brine.

- The energy saving ratio of (20\%-30\%) is achieved within the short duration of peak load up to 4 hours, and the lean load duration of (2-5) hours for cold water and cold brine accumulator.

- The volume of accumulator in case of water as secondary refrigerating refrigerant is closely to the brine accumulator at any conditions of milk cooling load.

- $\quad$ The increase of peak load duration leads to an increase in the power requirements and a drop in the energy saving efficiency. 


\section{REFERENCES}

[1] The dairy council, The importance of milk and dairy products as part of a healthy balanced diet, Available, www.milk.co.uk/page.aspx?intPageID=131; 2013. Last cited: January, 11, 2014

[2] Y.Cengel, Heat and Mass Transfer: A Practical Approach, third edition, McGraw-Hill, 2006.

[3] R. Trott, and T. Welch, Refrigeration and air conditioning, Third edition, Butterworth Heinemann, 2000.

[4] K. Wang, M.Eisele, Y. Hwang, and R. Radermacher, Review of secondary loop refrigeration systems, International Journal of Refrigeration,33 (2), (2010) 212-234.

[5] D.Kaijun, W.Zhiqiang, H.Baohu, H.Wenge, andChenzhaojie, The application of ice slurry for cooling milk, APEC Conference on Low-carbon Towns and Physical Energy Storage, Changsha, China, Paper ID: ACLE2013-E08-08, 2013.

[6] S.A. Tassou, J.S. Lewis, Y.T. Ge, A. Hadawey,and I. Chaer, A review of emerging technologies for food refrigeration applications, Applied Thermal Engineering, 30 (3), (2010) 263-276.

[7] P. L Ballaney, Refrigeration and air conditioning, Eleventh Edition, Khanna, 1998 